\title{
Um olhar estrangeiro, sete anos depois, sobre o processo criativo da Companhia do Chapitô, do Teatro Meridional e do Visões Úteis
}

\author{
NARA KEISERMAN
}

This article refers to the post-doctorate project on "Aspects of the Portuguese contemporary narrative scene", developed at the Lisbon University in 2010. The study has observed the creation processes of two plays, Cemitery of Pleasures by the Companhia do Chapitô, and 1974, by the Teatro Meridional, both groups being based in Lisbon. The Visões Úteis, based in Porto, was not rehearsing at the time, so the chosen line of research was to analyse their more significant previous pieces of work, as well as the ones in repertoire at that moment. Although there are quite remarkable differences between the languages and approaches worked by each of the three collectives, one common aspect that stands out in all three of them is the predominance of an improvisational creation mode, in which actors, at different levels, become co-creators of the scene.

COMPANHIA DO CHAPITÔ / TEATRO MERIDIONAL / VISÕES ÚTEIS / PORTUGUESE CONTEMPORARY THEATRE / CREATIVE PROCESS

O artigo se refere à investigação sobre «Aspectos da cena narrativa portuguesa contemporânea», para a qual foram selecionadas três companhias de teatro: a Companhia do Chapitô ${ }^{1}$, o Teatro Meridional ${ }^{2}$ e o Visões Úteis ${ }^{3}$. A ordem adotada para o que segue corresponde à cronologia de investigação em relação aos dois primeiros, dos quais acompanhei os ensaios dos espectáculos Cemitério dos Prazeres e $1974^{4}$, respectivamente. O contato com o Visões Úteis, por não estarem em período de criação de novo trabalho, se deu paralelamente aos outros. A escrita organiza-se em

1 http://chapito.org/ e http://companhia.chapito.org/.

2 http://www.teatromeridional.net/.

3 http://visoesuteis.pt/.

41974 foi encomenda do Teatro Nacional D. Maria II, como parte das comemorações dos cem anos da República. 
quatro partes. As três primeiras são relatos produzidos com algum grau de envolvimento e trazem observações sobre as especificidades encontradas; a quarta aponta elementos do teatro contemporâneo e verifica como se apresentam, comparativamente, no trabalho teatral de cada um dos coletivos investigados.

A Companhia do Chapitô, um dos ramos de atuação da instituição Chapitô - Colectividade Cultural e Recreativa de Santa Catarina, foi fundada em 1996 e contou com John Mowat como encenador dos espetáculos teatrais para adultos, a partir de 1999.

A investigação aqui tematizada teve início em agosto de 2010 . Os ensaios de um novo trabalho com os atores Jorge Cruz e Tiago Viegas haviam iniciado em julho. Estes deveriam se prolongar até meados de setembro, quando o Cão que morre não ladra ${ }^{5}$ entraria em digressão, com retomada em meados de dezembro para a estruturação dramatúrgica do material levantado, e estreia no início de $2011 .^{6}$ Pude acompanhar, portanto, a fase de improvisações dedicada principalmente à criação de personagens.

De acordo com a metodologia adotada, o trabalho iniciava com os atores realizando movimentos simples de aquecimento corporal e, sem solução de continuidade, sem nada que anunciasse qualquer mudança de estado, davam início ao jogo criador. Proposto por qualquer um deles, com resposta imediata do outro, os atores se precipitavam no jogo improvisacional.

Tal modo de criação imprime à cena a linguagem que é característica da Companhia, denominada por seus criadores de comédia física ou comédia visual, o que não deixa dúvidas: ali se faz comédia, ao que se pode acrescentar como qualitativos: inteligente e popular, iconoclasta (com o material trabalhado) e reverente (ao público que é sempre considerado); as palavras perdem terreno para a ação. Tais aspectos encontram coerência com o histórico e o repertório da Companhia, que privilegia a construção de espetáculos que se (des)estruturam ao redor de grandes personagens (Leonardo da Vinci, Camões, Medeia, Drákula) e de

5 http://companhia.chapito.org/?s=portfolio\&v=view\&p=29.

6 A estreia de Cemitério dos Prazeres foi a 27 de março (http://chapito.org/?s=events\&v=view\&e=67). 
grandes textos (Romeu e Julieta, D. Quixote, A Tempestade), que são abordados sem qualquer resquício de respeito autoral, com a finalidade assumida de fazer humor. Mantido esse foco incontornável, é realizado um trabalho prévio com o texto, em que são selecionadas as partes que podem render bons gags, sendo secundária a preocupação em contar a história que, presume-se, todos conhecem. Na encenação de D. Quixote, por exemplo, que considero um marco, e mais recentemente em Édipo ${ }^{7}$, restam poucas palavras de Cervantes e apenas um esboço de sua épica - o mesmo procedimento adotado com a tragédia de Sófocles.

No jogo improvisacional, há um despudor em relação ao trato com os materiais de cena: os objetos e o(s) outro(s) ator(es). Numa (quase) ausência de cenários, os objetos povoam a cena, na medida de sua utilidade para o efeito cômico visual. Não mais necessários, são jogados fora, lançados pelo ator que os manipula em (aparentemente) qualquer direção do espaço cênico. Esta mesma atitude aparece nos gestos e no modo como manipulam os corpos um/ns do(s) outro(s). Toda a gestualidade, altamente elaborada, de forte sofisticação e dificuldade técnica, é feita como se fosse nada, é jogada fora e ganha a aparência de casualidade. Seus próprios corpos são tratados como objetos de e para a cena, empenhados em fazer rir - e não em contar uma história, que é (quase) apenas um pretexto para tudo o mais.

Alguma coisa se modifica na encenação de Cão que morre não ladra, primeiro trabalho com uma construção dramatúrgica inédita. Desta vez, «o texto é exclusivo da sala de ensaios e das conversas entre os intérpretes e encenador», lê-se no programa da peça. Essa experiência abre espaço para o trabalho seguinte, cujos ensaios de criação presenciei.

$\mathrm{O}$ ator Jorge Cruz relatou que no primeiro dia de ensaio, parados, começaram a fazer sons de sirene e metralhadoras e imediatamente passaram a manipular suas roupas, criando figuras humanas com desenhos corporais enfatizados. Acredito que foi por influência do humor macabro de Cão, criado há pouco tempo pelos mesmos dois atores (e Marta Cerqueira), e mais o fascínio de Mowat pela nominação paradoxal de Cemitério dos Prazeres, que o novo trabalho se deu ao redor da exploração de um humor negro, com aspectos escatológicos.

O que vi foram dois atores nada menos que geniais naquilo que fazem, trabalhando sem qualquer pudor e empenhados em criar, criar e criar. Vi serem inventados e aprimorados cerca de quarenta e cinco personagens. Não há qualquer traço de psicologia. Há comportamentos corporais 
e vocais e a procura por qualquer coisa que sirva de impulso para a ação (cômica, é claro). Exemplos: o homem que vende fetos; Gaspar, o jovem atormentado que tem duas vozes (os atores pronunciam em uníssono as falas que um deles está improvisando) ${ }^{8}$; toda a família de Gaspar: sua avó, que canta cantigas infantis com voz de cantora lírica e usa um vestido preto com um profundo decote nas costas, sempre voltadas para a platéia; seu irmão, Big Feet, feito pelos dois atores, em plano baixo, um atrás do outro, dando a Big Feet quatro braços; um amigo de Gaspar, que emerge da mãe: o vestido sobe e ele surge, é batizado de Marcelo e não tem voz - Gaspar que tem duas, empresta uma para o amigo; o pai bêbado. E muitos outros, todos solidamente construídos, de modo a serem reconhecidos de forma imediata a partir da voz, do corpo, das roupas.

Durante as improvisações, os atores trabalham francamente com o diretor. Assim como passam do aquecimento para a cena, passam da cena para o diálogo com ele. Do mesmo modo, este interfere na cena sem qualquer veleidade. Diz o texto que intui, instrui e avalia e, apenas ocasionalmente, essas interferências interrompem o fluxo criador. Cada um dos atores reage de maneira diferente: um deles repete as falas «ditadas» por Mowatt. Outro considera-as já pronunciadas e segue adiante com o texto improvisado. Muitas vezes os vi perguntarem se tal ou tal ação «funciona», sem, é claro, interrompê-la. O trabalho de triangulação, fundamental na comédia, é, portanto, exercido desde a criação. Os elementos circenses são nítidos: trabalha-se para a platéia, a estrutura dramatúrgica é composta por gags, há na gestualidade elementos acrobáticos. Resisto, mas me rendo a dizer que são atores palhaços sem o nariz vermelho.

Os comentários do diretor vão determinando os critérios que cercam a linguagem e a concepção da cena. É muito simples: works or not e this is intuition. É bom quando é bizarre, strange, disgusting; não é bom quando é previsível, literal. Às observações dos atores quanto a it's not logic, a resposta invariavelmente é: never mind, it works.

$\mathrm{O}$ aprofundamento do trabalho fez crescer o número de figurinos e adereços, como bolsas, chapéus e sapatos. Num determinado momento, apareceu uma pá e em seguida, outra. Este era o cenário, já colocado no espaço, amontoado, quando entrávamos na Tenda. Lá, eu vi: cada ator vestir e fazer simultânea ou sucessivamente sem qualquer interrupção, três ou mais personagens; os atores experimentarem incansavelmente;

8 Os atores improvisam em inglês. Só depois de definidas as falas é que são vertidas para o português. 
o diretor ocupado com tempo-ritmo e foco muito precisamente definidos; os atores, com os personagens coveiros, lençol branco estendido no chão; andando ao redor, entre as roupas espalhadas, o som das pás no chão, vozes, sons estranhos, desencavando as roupas/personagens e colocando-os sobre o lençol, que finalmente carregam como um cadáver, saindo de cena.

Nice happy end, sentenciou o encenador, orgulhoso e satisfeito.

\section{TEATRO MERIDIONAL}

Estava na sede do Teatro Meridional no dia 13 de novembro de 2010. Miguel Seabra mostrou-me o jornal Público onde se lia a notícia anunciando que haviam recebido o Prêmio Europa-Novas Realidades Teatrais, por sua «política de repertório que alia níveis artísticos elevados à abertura a novos textos literários», e que «explora igualmente os textos de ficção e as tradições orais com uma curiosidade aguda, afirmando [...] a dignidade humana e reivindicando a tolerância e a aceitação do Outro» (Andrade, 2010: 8).

De fato, basta uma breve observação no repertório do Teatro Meridional para se perceber as vertentes principais de investimento artístico: a encenação de textos de novos autores; a adaptação de grandes textos da dramaturgia universal; o desafio a autores para arriscarem a escrita dramatúrgica, com especial interesse no universo lusófono; a criação de espetáculos em que a palavra não é o principal canal de comunicação.

Quanto à linguagem estética, no programa de Ki fatxiamu noi kui, espetáculo de estreia da Companhia, em 1992, encontra-se o fundamento do trabalho do Teatro Meridional, que ecoa ainda hoje:

\footnotetext{
Interessa-nos improvisar de uma forma nova: reaprendermo-nos, e aprender a contar histórias [...] Interessa-nos, também, de uma forma especial investigar o espírito mediterrâneo. E sobretudo, interessa-nos um teatro directo entre o actor e o público; sem grandes arquitecturas cenográficas, sem profundas análises dramatúrgicas: o teatro eterno onde o importante é como se conta, nesse encontro único entre o actor e o espectador.
}

Os ensaios se organizavam em nove horas de trabalho com o diretor, o assistente artístico (Jean Paul Bucchieri), o orientador de taiji qigong (Pedro Rodrigues), o diretor musical (José Mário Branco), a assistente de encenação (Leonor Cabral), em seis dias por semana durante quatro 
meses $^{9}$ - antecedidas por meia hora de aquecimento corporal, realizado individual ou coletivamente e finalizado por outra meia hora de desaquecimento.

Recebida por Miguel Seabra, este pôs-me a par do que já haviam realizado no primeiro mês de trabalho, dedicado primordialmente a estabelecer um sólido vínculo comunicacional, entre estes o encenador e seus assistentes. Entre as atividades já desenvolvidas, constavam o que Seabra denominou de disciplinas paralelas, que consistiam, por exemplo, em comprar um vaso de flores para oferecer a outro elemento do grupo, que se tornava responsável por cuidar da planta; em comprar onze cadeiras que cada um montou, decorou e passou a ser a sua cadeira.

A primeira atividade que presenciei foi o trabalho corporal orientado por Bucchieri, em que predominavam instruções como: não trabalhar pela espontaneidade; esclarecer todas as informações disponíveis; decidir sobre o que trabalhar. «Fujam de suas biografias!», exclamava, indicando um caminho de autossuperação e consciência. Estava claro ali o investimento no trabalho do ator sobre si mesmo, antes mesmo do trabalho do ator sobre o papel ou a peça a ser construída, assumindo traços fortemente pedagógicos.

Acreditando num trabalho coletivo («Busco um pulsar coletivo respeitando as individualidades», disse-me Seabra), apostava e investia na consecução de um coletivo coeso para a criação de $1974^{10}$ - uma peça com foco na identidade portuguesa, certa para um encenador que criara dois trabalhos considerados excelentes: Para além do Tejo (2004) e Por trás dos montes (2006).

Com o desenho dramatúrgico já concebido, encomendou-se a Luiz Francisco Parreira um texto filosófico, que o autor denominou de Notas dramatúrgicas. Organiza-se em: Prévio; Parte 1-Ditadura (O organismo, O movimento, A embriaguez, O segredo, O inimigo); Parte 2-A Revolução (A ocupação, A integração); Parte 3-O que nos resta (A memória, A família, A urna, A distracção, A dívida), Final. Trata-se de um texto denso, provocador, em que as indagações filosóficas têm o mesmo peso das

9 Seabra afirmou que costumava dedicar no mínimo doze meses para a criação de um espetáculo.

10 «1974 tem como objecto temático a identidade portuguesa, cruzando três períodos da história de Portugal: Ditadura, Revolução de Abril e a entrada na comunidade econômica européia, reflectindo ainda a nossa contemporaneidade» (programa da peça). Ouvi de Miguel Seabra que a peça se dava ao redor da ditadura de Salazar, da revolução e da ditadura da democracia. Há documentário sobre o processo de criação disponível em https://www.youtube.com/watch?v= 3bE4f0jpOnw. 
assertivas históricas. À primeira vista, pode-se dizer que não é um texto para ser encenado. Miguel Seabra identificou nele a matéria temática que serviu de eixo para as improvisações, temas como: vernissage, mocidade, despedida, casamento, soldados, procissão, carpideiras, imigrantes.

Além das disciplinas paralelas, o empenho processual para a constituição de uma unidade de pensamento criador abrangia outras estratégias que objetivam o aprimoramento de qualidades como atenção, escuta e prontidão. Estas abriam ou fechavam as sessões de trabalho. Um exercício bastante conhecido é aquele em que, com ou sem locomoção, os atores devem dizer os números de 1 até onde for possível, sem que dois falem ao mesmo tempo. Assisti uma bela execução desta proposta: serena, com silêncios prolongados, nenhum atropelamento. Isso significa um apurado senso de escuta coletiva, que certamente vazava na cena. Não há destaques interpretativos. Todos os atores estavam muito conscientes de seus papéis e funções, exercendo-as com a temperatura energética necessária, adequada. «Consciência» é uma palavra muitas vezes repetida por Seabra, que se desdobra em conceitos formulados também por Bucchieri. Um deles é o sentido de decisão («atitude cênica em que a decisão aparece», diz Seabra) utilizado aí de uma forma bastante aproximada do ideário brechtiano. O exemplo utilizado por Seabra no ensaio, «vais para a direita e decides ir para a esquerda», aliás, é semelhante à «determinação do não-antes-pelo-contrário» brechtiano (Brecht, 1978: 81).

Trabalhava-se com as duas modalidades de improvisação, a espontânea e a elaborada. Parecia-me, às vezes, que Seabra sabia bem o que pretendia da cena e usava o processo improvisacional como um procedimento de partilhamento da autoria da cena com os atores. Em outros momentos, principalmente quando deixava os atores por muito tempo executando tarefas aparentemente simples, para o que propunha muito poucas variações, ocorria-me que ele necessitava ver longamente as imagens que iam sendo processadas pelos atores para que pudesse construir a que o satisfizesse. Indagado sobre isso, disse-me que tinha apenas algumas hipóteses de solução.

Os comentários de Seabra às improvisações elaboradas pretendiam não propriamente arrumar a cena, que eventualmente sequer entraria no espectáculo, mas sim esclarecer princípios cênicos da linguagem adotada. Os objetivos são chegar ao osso, à essência; alcançar precisão e acabamento no início e final das ações, nos vetores direcionais das posturas e gestos, nas direções do olhar, no uso do ritmo; abolir ações, gestos ou atitudes de comentário; cada ação não deve pressupor a seguinte; muita 
atenção ao foco. Entre suas recomendações aos atores estão: «Não queremos mostrar nada, senão estamos lixadíssimos; não quero ver, não quero que os atores mostrem!»; «Não contem histórias! Deixem o público imaginar a história; já se percebeu, não se enterrem.» E conclui dizendo que «errar é fantástico».

Muito mais do que dirigir o espetáculo, vi Miguel Seabra dirigir os atores e empenhar sua fé naquilo que chamou, humoradamente, de «misto quente»: a técnica que alia resposta orgânica e marcação rigidamente desenhada.

Assisti à estreia e a mais duas apresentações de 1974. Posso atestar que o espetáculo continuava a ser modificado. Estas mudanças atendiam a uma necessidade de síntese, de eliminar o desnecessário. Seabra continuava buscando chegar ao osso.

VISÕES ÚTEIS

A investigação que pude realizar com o Visões Úteis foi bastante diferente das anteriores. Não frequentei ensaios, já que seu novo trabalho foi iniciado quando finalizava minha estada em Portugal. O que segue refere-se, portanto, a trabalhos já prontos com os quais tive algum tipo de contato. Estes foram: A Comissão ${ }^{11}$, criação do VU, em Coimbra; a abertura do Projeto Viagens com alma, no Porto; Boom \& Bang $^{12}$, em Aveiro, escrita a partir de The Power of Yes, de David Hare. Pude assistir, ainda, à palestra de Carlos Costa na abertura do seminário Encontros de Novas Dramaturgias Contemporâneas, em coprodução do São Luiz Teatro Municipal e do Colectivo 84. Boom \& Bange A Comissão são parte do que o grupo denomina de «teatro portátil»-que pode ser feito em qualquer lugar e cujos cenários, figurinos, adereços, técnicos e atores caibam num carro. Mas não é, certamente, apenas a praticidade que determina essas criações. Há um investimento que consiste em tirar o teatro do teatro, em problematizar o espaço teatral, em encontrar para cada assunto o seu local adequado.

A encenação de Boom \& Bang tem uma forte abordagem político-pedagógica ao buscar falar do «dia em que o capitalismo parou». Num tom humorado, os três atores apresentam (não se pode dizer que representam

11 Ficha artística disponível em http://www.visoesuteis.pt/index.php?option=com_k2\&view=item\&id $=104$ : comissao\&ltemid=59\&lang=pt.

12 Ficha artística disponível em http://www.visoesuteis.pt/index.php?option=com_k2\&view=item\&id =103: boom-bang\&ltemid=59\&lang=pt. 
e muito menos que encarnam) as figuras reais que agiram durante a crise, em Portugal, dando-lhes nome e sobrenome. A peça começa com a fala: «isto não é teatro». E, a partir daí, os actores estão liberados para investir numa linguagem híbrida, que fica entre a paródia, o grotesco e até mesmo um certo humor negro - porque não há piada alguma nas denúncias que são feitas ali.

A ideia para A Comissão partiu do desejo de uma reflexão sobre a linguagem como mecanismo de poder, por sua vez despertada pelo vídeo O Portuguesing de Zeinal, em que Zeinal Bava, então administrador da Portugal Telecom, discursa com termos técnicos, a maior parte em inglês - ininteligíveis para o cidadão comum. A situação elaborada pelos criadores do VU é simples. Passa-se numa sala de reuniões de um hotel (assisti no Hotel Íbis, em Coimbra). Ao redor da mesa, público e atores. Num dos lados, a Comissão Executiva (os atores) da Comissão de Acompanhamento da Implementação do Programa Estratégico Global Inter-Regional III, a CAI PEG/I-R III. À frente de cada um, uma placa onde se lê: Secretário de Estado (que não comparece), Representante da Área Metropolitana, Assessor do Secretário de Estado e Representante da Coordenação Regional. À frente de cada uma das pessoas da plateia, uma pasta, caneta, copo e garrafa de água, rebuçados e placas com vinte «funções representativas», entre as quais: Agência Local para as Indústrias Criativas, Direção-Geral das Artes, Direção-Geral do Patrimônio e outras de teor semelhante. Um a um, os membros da Comissão Executiva passam a expor, de modo ininteligível (há a personagem que só fala por siglas e expõe gráficos e estatísticas). Trata-se de convencer os membros das demais comissões (os espectadores) a votar a favor de um projeto que não fica claro em nenhum momento, mas que encerra - e isso é claríssimo - uma grande falcatrua. Os espectadores votam, os votos são contados e por um golpe do «regulamento», o projeto é aprovado e todos, inclusive os espectadores, brindam. Predominam, como no espetáculo anterior, a composição caricatural e a intenção crítica.

Considero importante, para situar as obras acima no contexto da produção artística do Visões Úteis, a referência ao Projeto Arte na Paisagem.

Foi a experiência denominada Visíveis na Estrada através da Orla do Bosque, que resultou no espetáculo Orla do Bosque, de 2001, que deflagrou um momento decisivo no trabalho do VU, em que os artistas apostam nas vivências em viagens como substrato para a criação. O Visíveis tem como foco indagativo os conceitos de Fronteira e de Europa e levou Ana Vitorino, Carlos Costa, Catarina Martins, Pedro Carreira (diretores artísticos e 
atores), Ágata Marques Fino (produtora), João Martins (músico e webdesigner) e Nuno Casimiro (escritor) a percorrerem dez mil quilómetros, a maior parte num carro pequeno, visitando cidades como Barcelona, Milão, Parma, Roma, Patras, Atenas, Munique e outras, em que entrevistaram intelectuais e artistas como Theo Angelopoulos, Daniel Libeskind, Umberto Eco, Emir Kusturica e muitos outros, previamente agendados. As observações de cada um dos viajantes foram sendo depositadas em um blogue (inaugurando também o uso dessa ferramenta para a escrita das peças) e resultou numa publicação impressa com o nome do projeto e excertos das entrevistas realizadas.

Acredito que foi essa experiência que efetivamente tirou o VU do espaço fechado ${ }^{13}$, expandindo suas criações não só para outras experiências análogas ${ }^{14}$ como para a criação de trabalhos que consideram como exemplos de Arte na Paisagem, os audiowalks. Coma Profundo (2002) é o primeiro audiowalk, a que se seguem Errare (2004); O Resto do Mundo (2007); Os Ossos de Que É Feita a Pedra (2009); A Língua das Pedras (2010).

No audiowalk, o comprometimento político praticado pelo grupo ganha literalidade na relação que o espectador (que já não pode ter esse nome) estabelece com a cidade. O espaço urbano é o local da ação. $\mathrm{O}$ «vivenciador» atua como um tipo especial de testemunha que entrelaça, na vivência proporcionada pelo audiowalk, elementos auditivos mais ou menos ficcionais com outros da realidade cotidiana da cidade, principalmente seu traçado, suas ruas, sua paisagem, suas alegorias. Força-se, assim, um olhar sobre a cidade, enfatiza-se a urbanidade como parte da identidade coletiva e individual, assim como se proporciona uma experiência profunda do ato de escutar. Objetivamente, o audiowalk é um passeio sonoro. Um «vivenciador» solitário escuta uma ou mais vozes gravadas em um CD portátil que transporta consigo e é conduzido por um percurso determinado que, no caso de alguns dos trabalhos do Visões Úteis, é desenhado no espaço público da pólis.

Coma Profundo ${ }^{15}$ é um passeio por partes da cidade do Porto. São duas vozes principais. A masculina conduz o caminho propriamente,

13 Até então, já haviam feito espetáculo em prisões e outros locais não teatrais.

14 Para a criação de Ventos, espetáculo estreado a 16 de janeiro de 2011, a equipe de criação viajou pelos lugares em que se passa D. Quixote de La Mancha, de Cervantes e ainda permaneceu em investigação em São Pedro da Afurada, em Vila Nova de Gaia, Portugal, situada numa região conhecida por seus fortes ventos. No endereço http://joaomartins.entropiadesign.org/category/visoes-uteis, a rota de D. Quixote: Castilla La Mancha, Alcazar de San Juan, Campo de Criptana, El Toboso, Consuegra.

15 As fichas artísticas e técnicas dos audiowalks estão disponíveis em http://www.visoesuteis.pt/ index.php?option=com_k2\&view $=$ item\&id=64: coma\&ltemid $=59 \&$ lang $=$ pt. 
determinando tanto o andamento quanto as direções da caminhada. Uma voz feminina tece comentários impressivos a propósito daquilo que o «vivenciador» está vendo. É uma experiência que não permite qualquer tipo de alienação. O participante precisa andar no ritmo que lhe é imposto, estar atento às instruções do tipo «dobre a direita no quarto poste», aos acontecimentos da rua, à presença das pessoas, aos sinais de trânsito; escutar simultaneamente os sons da rua e os que as vozes dos fones de ouvido impõem e é levado a exercer um olhar inusitado sobre a sua cidade.

Errare ocorre nas ruas da cidade de Parma. Afastando-se do documental presente em Coma Profundo, os criadores mantiveram o seu próprio olhar de estrangeiro sobre a cidade italiana, produzindo um audiowalk ficcional. Simultaneamente à descoberta da cidade, a personagem com quem o vivenciador se identifica está à procura de seu irmão. Este elemento dramático faz nublar o olhar para a realidade, ao mesmo tempo que o elemento propulsionador da ação, que é a procura, obriga o olhar atento.

Os Ossos de Que É Feita a Pedra traz o modelo audiowalk num outro formato. Realizado por encomenda da Fundácion Cidade da Cultura de Galícia, ocorre nas instalações da Cidade da Cultura da Galiza, em Santiago de Compostela, local da construção do Museu Nacional, Arquivo e Biblioteca, Teatro e Centro de Arte Internacional. A trajetória percorrida pelo visitante é circunscrita a este espaço-deixa de ser um percurso solitário, embora permaneça o fone de ouvido, ou seja, o som não é partilhado. O conteúdo literário traz informações sobre o local e sua construção, assim como reflexões sobre o sentido do ato humano de construir.

A Língua das Pedras inaugura uma nova etapa na linha de intervenção artística Arte na Paisagem. Trata-se de uma instalação multimídia que marca o encerramento do evento Toute l'Europe à Cluny, de comemoração dos 1100 anos da Ordem de Cluny. Norteados pelo objetivo de traçar uma cartografia da herança espiritual da Ordem, os criadores percorrem os mesmos doze caminhos que, na Idade Média, partiam da cidade de Cluny, visitando monumentos religiosos, entrevistando seus habitantes, etc. Este material é a base para a instalação $A$ Língua das Pedras, que ocupa os seis pisos da medieval Tour des Fromages.

A Língua das Pedras abre caminho para o projeto Viagens com Alma, realizado por convite da Diocese do Porto, composto por um evento de abertura com música e projeções no claustro do Mosteiro de São Bento da Vitória, e quatro audiowalks de cerca de quinze minutos, percorrendo trajetórias que incluem edifícios da Diocese. Volta o modelo do 
vivenciador solitário e o foco na pólis, contemplando a forte imbricação da Igreja na construção da identidade portuguesa.

Assim como em Arte na Paisagem, as produções denominadas pelo VU como espetáculos estão cada vez mais distantes do teatro canônico que acontece no edifício teatral - seguindo, dessa forma, uma forte tendência dos grupos que, com seu trabalho, estão ampliando universos, abrindo sem medo a cena para novas experiências e linguagens.

Para o breve estudo comparativo dos princípios, linguagens e processos de criação das três companhias, utilizo como parâmetros as noções de teatralidade, de dramaturgia textual e cênica, de autoria, e da pedagogia do ator e do espectador.

As três companhias foram fundadas nos anos noventa do século $\mathrm{xx}$, quando se discutiam os conceitos de teatralidade (Pavis, 2008), teatro performativo (Féral, 2015) e teatro pós-dramático (Lehmann, 2007) - que em maior ou menor grau e em diferentes aspectos, por escolha, influência ou contaminação determinam as suas criações. Opto por situar os trabalhos teatrais aqui examinados como dentro do campo da teatralidade, entendido como um conceito-chave aglutinador e de certa forma genérico (Bulhões, 2001: 181): abriga as experiências cênicas em que se des-hierarquizam os elementos constitutivos da cena, com a consequente diluição da noção de autoria; a ação parece perder espaço para a situação; a presença do ator (quase um narrador) tende a substituir a personagem ficcional; os encadeamentos podem se estruturar sem uma lógica aparente; pretende-se do espectador uma ação inteligente e/ou sensível.

É interessante observar as fichas artísticas e técnicas de Cemitério dos Prazeres: «Criação Colectiva; Direcção Artística | José Carlos Garcia | John Mowat; Encenação | John Mowat» ${ }^{16}$; 1974: «Criação Teatro Meridional | Encenação Miguel Seabra ${ }^{17} ; A$ Comissão (opto por ter este trabalho como referência): «texto e direção Ana Vitorino e Carlos Costa, colaboração na dramaturgia Nuno Casimiro ${ }^{18}{ }^{8}$ Em todas, nota-se a aposta no coletivo. Na produção do Chapitô, está o termo consagrado de «criação coletiva», 
e encenação de Mowat - que foi, efetivamente, o que vi nos ensaios. Os dois atores e o encenador são autores da cena, a que este último dá uma versão organizada, a partir da seleção de ideias e do material próprio da composição atorial oferecido pelos atores em ação criadora de caráter improvisacional. Quando Seabra anuncia em todas as produções a «criação» como do Teatro Meridional, está declarando um pensamento coletivo, de que participa, pelo menos, sua parceira de sempre, Natália Luiza (ainda na Ficha de 1974, lê-se: «Direcção Artística do Teatro Meridional Miguel Seabra e Natália Luiza»). O trabalho do Visões Úteis é sustentado pela parceria entre Ana Vitorino e Carlos Costa.

As discussões sobre a autoria daquilo que o espectador recebe abarcam a já antiga e superada polaridade entre textocentrismo e cenocentrismo e chega às noções de dramaturgia corporal, ou dramaturgia do ator e de dramaturgia cênica ou escrita cênica. Cemitério e 1974 são exemplares: constituídos de poucas palavras, prevalece uma dramaturgia da cena em que as corporeidades estão em primeiro plano: é a comédia física ou visual do Chapitô, habitante não casual de uma tenda circense ${ }^{19}$, e «a lógica de construção cénica e artística dos espectáculos do Teatro Meridional, [em que] a linguagem cénica, essencialmente não verbal, [é] construída através da fisicalidade do actor [...]». O mesmo não acontece no VU. Há um comprometimento assumido na apresentação do seu projeto artístico, que parece, por seu discurso, não poder prescindir das palavras:

No Visões Úteis o projecto estético cresce em sintonia com uma forte motivação ética - poderemos mesmo dizer política - numa constante reflexão acerca do sentido contemporâneo de fazer arte - e em particular artes performativas - que quotidianamente marca as opções de trabalho e agudiza a consciência da responsabilidade social e política para com as comunidades envolventes. (http://visoesuteis.pt/)

Tal afirmação não elimina um caráter político que se pode observar claramente nas produções do Teatro Meridional, principalmente. Há nelas um compromisso que se evidencia nos espetáculos em que investigam questões relativas à história política e social e à identidade portuguesa e 
mesmo lusófona. O trabalho da Companhia do Chapitô atinge uma outra dimensão do político, em que o riso é entendido como agente transformador «pela dimensão crítica que suscita» ${ }^{20}$. O político que observo nas criações do Chapitô se dá pelo exercício que proporciona ao espectador ao promover o riso às vezes desenfreado, outras cauteloso ou mesmo nervoso, e que faz da plateia, naquele momento, uma verdadeira assembleia.

Dificilmente se pode nomear as figuras criadas pelos atores como personagens dramáticas. Considero este um dos aspectos mais nítidos e mesmo evidente da opção contemporânea que privilegia a dramaturgia cênica em detrimento da canônica; da situação, no lugar da ação. A estrutura de $A$ Comissão é principalmente organizada em monólogos, em que cada «personagem», como um narrador épico, dirige-se aos espectadores (naquele momento fazendo o «papel» de representantes de outras comissões). O uso das aspas pretende deslocar a categoria intrínseca, para apontar um alargamento na noção: o «eu» do discurso está fora do ator. Não há qualquer resquício de psicologia no desempenho dos atores, que dão corpo e voz às várias figuras em Cemitério e em 1974: o que o ator faz é compreender a situação e agir dentro dela, fazê-la acontecer, com desenhos corporais acentuados (Cemitério) ou num traçado mais próximo da cotidianidade (1974). Interessante que tanto o Chapitô quanto o Teatro Meridional descendem assumidamente da commedia dell'arte. No entanto, parece que esta descendência manteve-se concretamente nas criações da primeira, tendo-se diluído na segunda.

Há, no trabalho dos quatro encenadores, Mowat, Seabra, Costa e Vitorino, uma pedagogia da criação, uma pedagogia da encenação e uma pedagogia do espectador em diferentes dimensões e aspectos. Poderia afirmar a necessidade de qualidades muito específicas para o ator nas encenações de Mowat, como disponibilidade corporal, presença e prática ágil no jogo teatral, agilidade e experiência na criação textual. Mowat não vai «ensinar» os atores a fazerem o que a cena necessita, mas o ator que possui as habilidades certamente vai se tornar expert se souber ouvir e seguir a suas indicações. No trabalho de Seabra, há uma pedagogia assumida em relação aos atores. O trabalho com eles, para eles - antes da abordagem direta do espetáculo a ser criado - remete à ideia de «trabalho sobre si mesmo», herança de Stanislavski (Quilici, 2015), e se singulariza pelo fato de o encenador não ter a perspectiva de formar um coletivo de 
atores com o qual vá, necessariamente, continuar a trabalhar. Costa e Vitorino têm desde a fundação do VU e em toda a sua trajetória um olhar inarredável sobre o espectador, numa relação que vai além da arte e se move para uma pedagogia: pretende promover o conhecimento de assuntos políticos, sociais relevantes do momento presente e instalar uma discussão frutífera, que possa se traduzir em ações efetivas no campo de atuação de cada um.

Comum aos três coletivos, a dedicação incansável e por vezes exaustiva ao exercício de, como queria Meyerhold, aqui citado de memória, «treinar, treinar, treinar». A Companhia do Chapitô, o Teatro Meridional e o Visões Úteis seguem apostando nas premissas que os sustentam desde sua fundação, revelando um trabalho enraizado em profundas convicções, que permite que a linguagem de cena evolua em alcance e sofisticação.

Este exercício de memória sobre uma pesquisa desenvolvida há sete anos é o resultado de uma necessidade de compartilhar a experiência, de dar a conhecer processos de trabalho teatral tão especiais e importantes para o teatro que se faz hoje.

\section{REFERÊNCIAS BIBLIOGRÁFICAS}

ANDRADE, Sérgio C. (2010), «Prémio europeu para o Teatro Meridional», Público, Lisboa, 12 de novembro, p. 8. BRECHT, Bertolt (1978), Estudos sobre Teatro, trad. Fiama Hasse Pais Brandão, Rio de Janeiro, Nova Fronteira.

Bulhões-Carvalho, Ana Maria (2011), Da Cena ao Texto: Configurações da teatralidade, in Da Cena Contemporânea, Porto Alegre, ABRACE, pp. 180-87.

FÉRAL, Josette (2015), Além dos Limites: Teoria e Prática do Teatro, São Paulo, Perspectiva.

Lehmann, Hans-Thies (2007), Teatro Pós-Dramático, trad. Pedro Süssekind, São Paulo, Cosac Naify (ed. port. Teatro Pós-Dramático, trad. Manuela Gomes e Sara Seruya, Orfeu Negro, 2017).

MEYERHOLD, Vsévolod (2012), Do Teatro, São Paulo, Iluminuras.

PARREIRA, Francisco Luís (2010), 1974, texto de trabalho, Lisboa, Teatro Meridional.

PAVIS, Patrice (2008), Teatro no Cruzamento de Culturas, São Paulo, Perspectiva.

QUilici, Cassiano Sydow (2015), «Stanislavski, Grotowski e as transformações do "homem ator»», in $O$ Ator-Performer e as Poéticas da Transformação de Si, São Paulo, Annablume, pp. 75-87.

TEATRO MERIDIONAL (1992), Ki fatxiamu noi kui: o projecto, programa da peça.

vitorino, Ana / costa, Carlos et al. (2003), Visíveis na Estrada através da Orla do Bosque, Vila Nova de Famalicão, Quasi.

- (2004), Caderno II - Estudos e Orla do bosque, Porto, Visões Úteis.

- (2006), Caderno III - Coma profundo e Errare, audiowalk, Porto, Visões Úteis.

- (2007), O Resto do Mundo, texto de trabalho.

- (2009), Os Ossos de Que É Feita a Pedra, audiowalk, texto de trabalho.

- (2010a), Boom \& Bang, texto de trabalho.

- (2010b), A Comissão, texto de trabalho.

- (2010c), A Língua das Pedras, audiowalk, texto de trabalho. 


\section{NARA KEISERMAN}

Nara Keiserman concluiu mestrado em Artes: Teatro pela Universidade de São Paulo USP (1986), com a dissertação A preparação corporal do ator: uma proposta didática. Tem dias que a gente se sente; doutoramento em Teatro pela Universidade Federal do Estado do Rio de Janeiro - Unirio (2004), com a tese Caminho pedagógico para a formação do ator narrador; pós-doutoramento pela Universidade de Lisboa (2011), com investigação sobre Aspectos da cena narrativa portuguesa contemporânea. É professora na Escola de Teatro da Unirio, actuando na licenciatura e na pós-graduação em Artes Cénicas. Coordena a investigação «Actor rapsodo: pesquisa de procedimentos para uma linguagem gestual» e é responsável pelas disciplinas de Movimento do Departamento de Interpretação. É líder do Grupo de Pesquisa Artes do Movimento e coordenadora do Laboratório Artes do Movimento. As suas experiências na área têm ênfase no trabalho do actor, com desdobramentos nos seguintes temas: actor narrador, linguagem gestual, teatro narrativo, teatro e espiritualidade. Publicou capítulos e artigos em revistas especializadas. Tem trabalhos como actriz, encenadora e preparadora corporal de elencos. 